Mat. Res. Bull. Vol. 5, pp. 983-988, 1970. Pergamon Press, Inc. Printed in the United States.

\title{
CAUSE OF DISCREPANCIES IN DIFFUSION COEFFICIENT DATA AS OBTAINED FROM THE SINTERING EXPERIMENTS OF OXIDES
}

Franklin F. Y. Wang and Chandra P. Khattak Department of Materials Science State University of New York at Stony Brook Stony Brook, L. I., New York 11790

(Received May 6, 1970 and in final form September 14, 1970; Refereed) ABSTRACT

It is shown that when the distribution of particle sizes is included, the calculated diffusion coefficient value from the sintering experiment can be many orders of magnitude greater than the usual calculated value which was based on an average particle size.

One of the most puzzling facts in the sintering experiments of axides is the large diffusion coefficient which can be obtained from all the diffusion models of sintering. In the case of aluminum oxide (1) the calculated values were higher than those for aluminum and oxygen by two and four orders of magnitude. Sintering data on $\mathrm{NiO}$ (2) showed a factor of four orders of magnitude over the diffusion data. Coble and Gupta (3) showed that a correction in the determination of equivalent grain size can decrease the calculated diffusion coefficient values. This paper shows that by taking the particle size distribution into consideration, a substantial reduction in the calculated diffusion coefficients is readily feasible.

Following Lay and Carter (4), the change in linear dimension can be expressed as

$$
\frac{\Delta \ell}{\ell}=\left(\frac{\mathrm{AD}_{\mathrm{A}} \mathrm{t}}{\mathrm{r}_{\mathrm{A}}{ }^{3}}\right)^{\mathrm{p}}
$$




$$
\begin{aligned}
\mathrm{p} & =0.33 \text { grain boundary diffusion } \\
\mathrm{p} & =0.50 \text { bulk diffusion } \\
\text { where } \quad \mathrm{A} & =\frac{\mathrm{C} \Omega}{\mathrm{kT}} \\
\mathrm{t} & =\text { sintering time } \\
\mathrm{r}_{\mathrm{A}} & =\text { equivalent grain size radius } \\
\mathrm{D}_{\mathrm{A}} & =\text { calculated apparent diffusion coefficient }
\end{aligned}
$$

If the particle distribution in volume fractions is $f\left(r_{1}\right)$ then, the above expression (eq. (1)) can be written as:

$$
\frac{\Delta l}{\ell}=(A D t)^{p}\left[\sum_{l} f\left(r_{2}\right)\left(r_{l}\right)^{-3 p}\right]
$$

The expression eq. (2) is due to the additive property of $(\Delta \ell / \ell)$,

and is based on a simple model of packing of particles. Instead of the usual sintering model where compacts of identical spheres were assumed, this present model assumes that each packing layer consists of particles of same size. The interactions between particles of different sizes are not taken into account. However, in this simple model, particles of different sizes are in contact only between packing layers. Therefore, these interactions, if taken into account, would further increase the $\mathrm{D}_{\mathrm{A}}$ values. The neglect of these interactions does not invalidate the conclusions in this paper. The ratio of the calculated diffusion coefficients in eqs. (1) and (2), namely $D_{A} / D$ is given by:

$$
D_{A} / D=\left[\frac{\sum_{l} f\left(r_{\imath}\right)\left(r_{l}\right)^{-3 p}}{\left(r_{A}\right) 3 p}\right]^{1 / p}
$$

To provide a quantitative value for $\mathrm{D}_{\mathrm{A}} / \mathrm{D}$, we assume a discrete particle distribution $f\left(r_{1}\right)$ which at specified regular intervals, has the value of a log normal (Gaussian) distribution whose average value is $r_{A}$. 
For a comparison, the distribution is made to vary in the following way, First, the average radius value $r_{A}$ is assumed to be a constant value, for example, $\mathrm{r}_{\mathrm{A}}=2$ is used throughout this study. The discrete distribution is

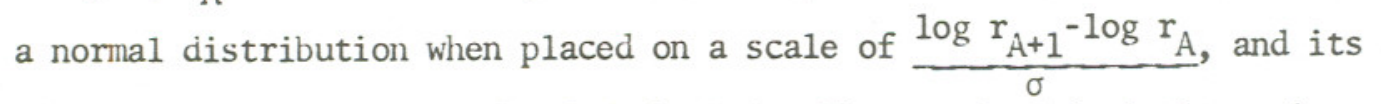
regular interval, $\Delta z$, is fixed to be 0.1 . The standard deviation $\sigma$ is varied on a linear scale with $\log \mathrm{r}_{\mathrm{A}}$.

$$
\begin{aligned}
\sigma & =q \log r_{A} \\
\Delta z & =\frac{\log r_{A+1}-\log r_{A}}{\sigma}
\end{aligned}
$$

From (5) it shows that

$$
r_{l}=r_{A}\left(q z_{l}+1\right)=r_{A}(1+l(\Delta z))
$$

For a range of $\mathrm{q}$ values, the ratios of $\mathrm{D}_{\mathrm{A}} / \mathrm{D}$ for either grain boundary diffusion or bulk diffusion are shown in Table 1 . The discrete distribution has 34 intervals. At each interval, the distribution has the value of the cumulative Gaussian distribution at that point. Columns 3 and 5 in lable 1 represent the radius values at the first interval on both sides of the average value $r_{A}(=2)$, and columns 4 and 6 represent the radius values at the 17th intervals on both sides of $r_{A}$. The sensitivity of $\mathrm{D}_{\mathrm{A}} / \mathrm{D}$ is in the neighborhood of 1 . Therefore, the $\mathrm{D}_{\mathrm{A}} / \mathrm{D}$ values, which are less than 1 , can be approximated to be 1 . It is therefore shown that for reasonable particle distributions, large values of apparent diffusion coefficients can be readily obtained.

The conclusions are:

1) The particle sizes contribute substantially to the determination of diffusion coefficients from sintering experiments.

2) The sensitivity of the calculated diffusion coefficients value to the distribution of small particle sizes renders itself useless, since the small particle size ranges are the least accurately determined. 
Dependence of Ratios $\left(D_{A} / D\right)$ on the Width Increment, $q$, of Normal Distribution of Particles

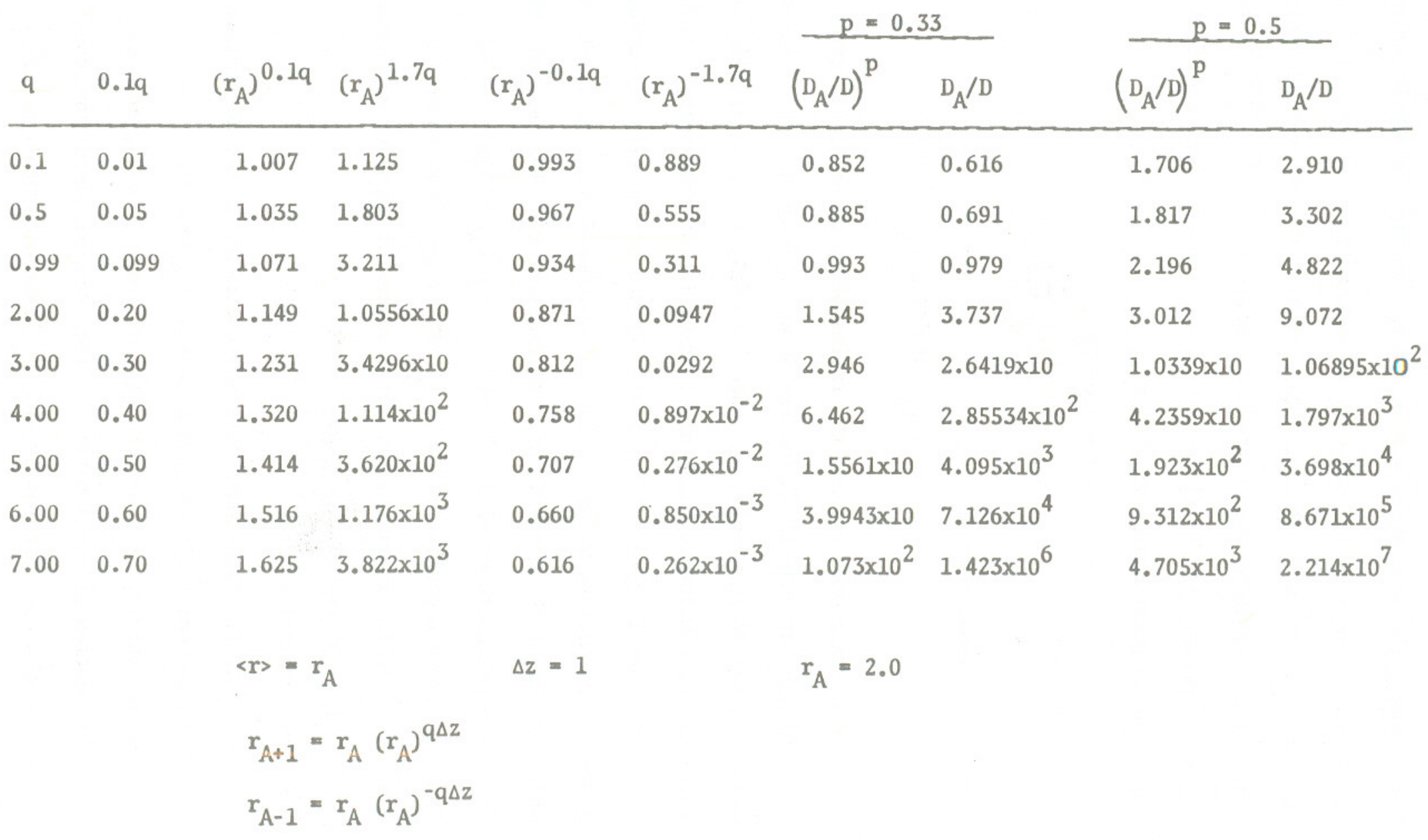


3) The great range of the variability of the calculated diffusion coefficient values from sintering experiments does not support the common usage of identifying these diffusion values with that of the cation diffusion in the oxides. They may, indeed, be the oxygen diffusion.

\section{References}

1. R. L. Coble, J. App1. Phys. 32, 793 (1961).

2. R. M. Jodlowski and G. C. Kucznski, Sintering and Related Phenomena, edited by G. C. Kucznski, N. A. llooton and C. F. Gibbon, pps. 553-563. Gordon and breech, New York (1967).

3. R. L. Coble and T. K. Gupta, Sintering and Related Phenomena, edited by G. C. Kuczynski, N. A. Hooton and C. F. Gibbon, pps. 423-444. Gordon and Breech, New York, (1967).

4. K. W. Lay and R. E. Carter, J. Am. Ceram. Soc. 52, 189 (1969).

5. Edwin L. Crow, Francis A. Davis, Margaret W. Maxfield, Statistics Manual, Dover, New York (1960) Table 1. Cumulative Normal Distribution, p. 229. 
